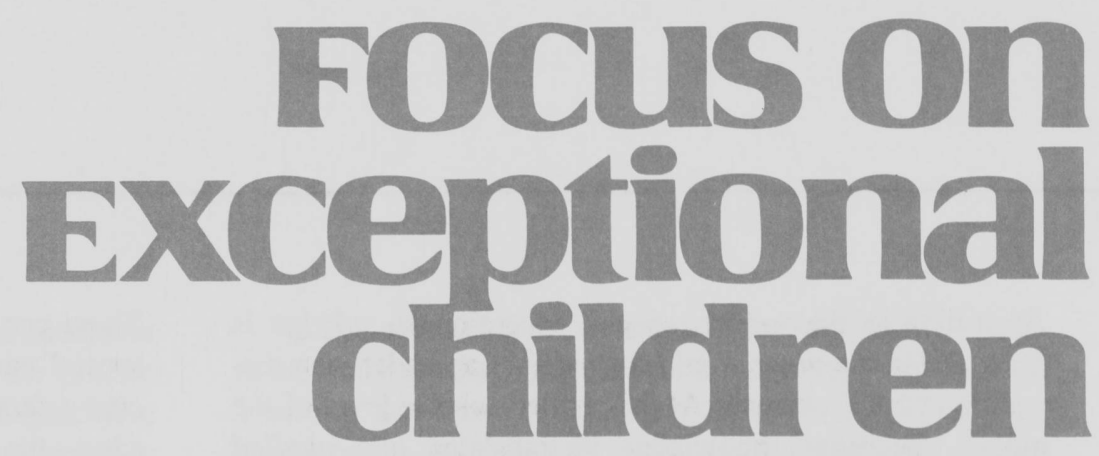

\title{
The Crisis in Special Education Knowledge: A Perspective on Perspective
}

Thomas M. Skrtic

Special education is a conglomeration of a number of sub-fields. Historically, the sub-fields have been organized around so-called categories of "exceptionality" or "disability." As such, each sub-specialty within special education has its own professional knowledge, which reflects the presumed differences among the categories of exceptionality. Nevertheless, behind the surface differences each of the sub-fields subscribes to a basic foundation of general special education knowledge. What is of interest here is this tradition of general special education knowledge, which, for convenience sake, we will refer to simply as special education knowledge.

Another challenge in discussing special education knowledge is deciding on whose version to accept as the genuine article. To draw a crude analogy, asking the special education community about the nature of its professional knowledge is like asking a school of fish about the nature of water. Neither group can be depended upon for an adequate answer because these matters are so basic to them that they are largely taken for granted. Thus, bringing a number of perspectives to bear upon the subject will be helpful. The best way to do this is to consider some of the criticisms of traditional special education knowledge. There is no shortage of such criticism.

Special education knowledge follows a threefold model of professional knowledge (Schein, 1972, p. 43):

1. An underlying discipline or basic science component upon which the practice rests or from which it is developed.

2. An applied science or "engineering" component from which many of the day-to-day diagnostic procedures and problem-solutions are derived.

3. A skills and attitudinal component that concerns the actual performance of services to the client, using the underlying basic and applied knowledge. 
According to the model, special education knowledge is grounded in the theoretical knowledge of an underlying discipline or basic science. At the applied science level of the model, theoretical knowledge is translated into applied knowledge, or models, techniques, and procedures for application to the day-to-day problems of practice. Finally, special education's theoretically grounded applied knowledge yields practical knowledge, which is transmitted to the special education practitioner-in the form of knowledge, skills, attitudes, and norms - through an extended program of training and indoctrination that constitutes professional education in special education. The performance of special education professional services to clients - by the special education teacher, clinician, or therapist-is based on practical knowledge, which is conceptualized as the result of applying theoretical knowledge to solving problems of special education practice.

Historically, two general types of criticism of special education knowledge are found: practical and theoretical.

\section{FOCus on
Exceptional children}

FOCUS ON EXCEPTIONAL CHILDREN (ISSN0015-511X) (USPS 203-360) is published monthly except June, July, and August as a service to teachers, special educators, curriculum specialists, administrators, and those concerned with the special education of exceptional children. This journal is abstracted and indexed in Exceptional Child Education Resources, and is also available in microform from Xerox University Microfilm. Ann Arbor, Michigan. Subscription rates, $\$ 18.00$ per year. Copyright (c) 1986, Love Publishing Company. All rights reserved. Reproduction in whole or part without written permission is prohibited. Printed in the United States of America. Second class postage is paid at Denver, Colorado.

POSTMASTER: Send address changes to:

Love Publishing Company

Executive and Editorial Office

1777 South Bellaire Street

Denver, Colorado 80222

Telephone (303) 757-2579

\section{EDITORIAL BOARD}

Edward L. Meyen

University of Kansas
Glenn A. Vergason Georgia State University

Richard J. Whelan

University of Kansas Medical Center
Stanley F. Love Publisher
Carolyn Acheson Senior Editor
These can be understood in terms of the above model of special education professional knowledge. Practical criticism refers to criticism of special education practical knowledge- the knowledge and skills that underwrite the actual performance of services to the client by the professional special education practitioner. As we will use the term, theoretical criticism refers to criticism of both special education theoretical and applied knowledge- both the theoretical knowledge of the underlying discipline or basic science and the applied knowledge engineered from theoretical knowledge by special education applied researchers.

\section{PRACTICAL CRITICISM OF SPECIAL EDUCATION KNOWLEDGE}

Of the two general types of criticism, practical criticism has been the most visible and has had the greatest impact on the way special education services are delivered to students. Practical criticism, centered on the actual practice of special education, has been mounted by parents, consumers and advocates, and, to some extent, special educators themselves (e.g., Dunn, 1968; Blatt \& Kaplan, 1966). Historically, critical debate has revolved around the relationship between regular and special education in terms of the identification, placement, and education of students with disabilities. In fact, much of today's special education practice has evolved as a response to yesterday's practical criticism. Although this mutually-shaping relationship between practical criticism and changes in practice can be traced over the entire history of special education, in the modern era its most intense and fruitful phase was the 10 -year period from 1965 to 1975.

At the height of the social-political ferment of the 1960s, parents and consumers and advocates used the period's increased sensitivity to human and civil rights to mount a case against special education as it was practiced at that time. This particular round of practical criticism led to victories in courtrooms and statehouses across the country and eventually in the U.S. Congress, which ultimately redefined special education practice under the rubric of the statutory mandate of Public Law 94-142, The Education for All Handicapped Children Act of 1975.

PL 94-142 essentially mandates a free, appropriate public education for all students with disabilities in the least restrictive-most integrated - environment possible. It changed special education practice by changing its structural relationship to regular education and by extending to students and their parents certain constitutional rights and procedural safeguards, including due process of law. Of course, PL 
94-142 did not end critical commentary on special education practice. Public debate and legal action over the precise meaning of "appropriate education" and "least restrictive environment," among other concepts, have continued over the 10 years of the law's implementation (Turnbull, 1986).

But the point to be made here is that practical criticism led to changes in special education practice. An important point to grasp is that the changes brought about by PL 94-142 did not result from theoretical criticism. The law itself (and the changes in practice that have resulted from it) was the product of moral, ethical, legal, and political arguments against special education practice at that time (Ballard-Campbell \& Semmel, 1981; Biklen, 1985).

\section{THEORETICAL CRITICISM OF SPECIAL EDUCATION KNOWLEDGE}

Ultimately, theoretical criticism of special education knowledge is also criticism of special education practice. But, as it is used here, it is essentially criticism of the manner in which basic science theory is applied at the applied science level of special education knowledge. Thus, the targets of theoretical criticism are special education applied researchers, developers, and policy analysts within universities and at all levels of government. Whereas practical criticism of special education has been mounted primarily by consumers and advocates, theoretical criticism tends to come from the academic disciplines-primarily from the social sciences-and is based on three claims: atheoretical, confounded theory, and wrong theory.

\section{The Atheoretical Claim}

The first type of theoretical criticism is based on the claim that special education applied research and practice operate in the absence of any guiding theory (e.g., Bogdan \& Kugelmass, 1984; Rist \& Harrell, 1982; Tomlinson, 1982). It is argued that, instead of being grounded in the theories of an underlying discipline or basic science, special education applied research and practice are guided by a narrow set of unconscious assumptions. Bogdan and Kugelmass (1984) summarized special education's unconscious assumptions as follows:

(1) Disability is a condition that individuals have; (2) disabled/typical is a useful and objective distinction; (3) special education is a rationally conceived and coordinated system of services that help children labelled disabled; (4) progress in the field is made by improving diagnosis, intervention and technology. (p. 173)
While not denying the accuracy of the Bogdan and Kugelmass analysis of special education's assumptions-indeed, I believe that these are precisely the basic beliefs that implicitly serve as guides for research and practice in special education-when examined more closely, they reveal that the "atheoretical" part of their claim cannot be justified. The first two assumptions - that disability is a condition that people have, and that disabled/typical is a useful and objective distinction-derive directly from theories of deviance in the basic sciences of psychology and biology. The third assumption - that special education is a rationally conceived and coordinated system of services-actually has two theoretical sources. The first source is the positivist theory of knowledge, which serves as the foundation for the dominant model of professional knowledge (Schon, 1984; Schein, 1972; Glazer, 1974). Special education, like all professional fields, implicitly believes that its knowledge is the end product of a rational system of knowledge production. The second source of this assumption is a general theory of organizational rationality, which until recently has dominated thinking and writing about all organizations, including schools (see Clark, 1985; Weick, 1985). It has been so central to the organization of industrialized societies that it permeates the consciousness of all industrialized people, even if they don't realize it.

The fourth assumption - about the nature of progress - derives from the notion of cumulative knowledge that underwrites the positivist theory of knowledge, as well as the dominant conceptualization of scientific progress (discussed later). The point is that, although special education research and practice are guided by unconscious beliefs, one can hardly claim that these beliefs have no theoretical basis at all. The real problem for special education is the unconscious - and thus noncritical—nature of these basic beliefs, and not whether they are grounded in theory.

\section{The "Confounded Theory" Claim}

The second type of theoretical criticism is based on the claim that special education applied research and practice confound theories. The best example of this type of criticism is Jane Mercer's (1973) explanation of the way biological and psychological theories of deviance are confounded within the clinical perspective of mental retardation. Derived from medicine and psychology, the clinical perspective is the familiar frame of reference that guides research and practice in the helping professions, including special education. This perspective contains two contrasting theories of 
"normal/abnormal": the pathological model from medicine (biology), and the statistical model from psychology.

The pathological model defines impairments according to the presence or absence of observable biological symptoms. Biological processes that interfere with system preservation are "bad," or pathological; those that enhance the life of the organism are "good," or healthy. Thus, the pathological model is bipolar: At one pole is normal (i.e., the absence of pathological symptoms and health); at the other pole is abnormal (i.e., the presence of pathological symptoms and illness or "unhealth"). The pathological model is essentially evaluative: To be abnormal is to be unhealthy; this is "bad" and should be prevented or alleviated.

The statistical model is based on the concept of the normal (or bell-shaped) curve: In essence, an individual's attributes can be described by his or her relative position in a frequency distribution of other persons measured on those attributes. Whereas the pathological model defines abnormality as the presence of observable pathological symptoms, the statistical model defines abnormality according to the extent to which an individual varies from the average of a population on a particular attribute. Unlike the bipolar pathological model, which defines only one type of abnormality, the statistical model defines two types of abnormality: abnormally large and abnormally small amounts of the measured characteristic. Whereas the pathological model is evaluative (pathological signs are always "bad"), the statistical model is evaluatively neutral; whether high is "good" and low is "bad" or high is "bad" and low is "good" depends on the attribute being measured. And whether it is "good" or "bad" to be high or low on any particular attribute is defined by society. As far as the attribute of intelligence, in our society abnormally high is "good," and abnormally low is "bad."

Both models are used to define mental retardation-the pathological model for assessing biological manifestations and the statistical model for assessing behavorial manifestations, which are not comprehensible within the pathological model. Although instances of moderate to severe/profound mental retardation are associated with observable patterns of biological symptoms, and are thus comprehensible under the pathological model, most individuals labeled "mildly mentally retarded" do not show any biological signs. In these instances the statistical model is used and a low score on an intelligence (IQ) test is accepted as a symptom of pathology. The problem is that when the models are used in conjunction with one another, the tendency is to transpose them, turning behavioral patterns into pathological signs. Mercer (1973) explained the confusion by saying that:
The implicit logic that underlies this transformation is as follows: Low IQ = "bad" in American society: a social evaluation. "Bad" = pathology in the pathological model. Therefore, low IQ = pathology. Thus, IQ, which is not a biological manifestation but is a behavioral score based on responses to a series of questions, becomes conceptually transposed into a pathological sign carrying all of the implications of the pathological model. (pp. 5-6)

Although Mercer identified a number of negative implications of the conceptual transposition, the primary implication-and the point of interest here-is the fact that mental retardation ends up being regarded as an attribute of the individual. The clinical perspective regards mental retardation as a pathological condition, and the pathology is considered to be an objective condition that individuals have. Although Mercer limits her criticism to the area of mental retardation, the same type of criticism has been made for special education research and practice in the area of learning disabilities (Rist \& Harrell, 1982; Schrag \& Divorky, 1975), and particularly in the area of emotional disturbance (Algozzine, 1976, 1977; Apter, 1982; Hobbs, 1975; Rhodes, 1970; Ross, 1980; Swap, 1978). Together with mild mental retardation, these areas make up the majority of all students identified as disabled.

\section{The "Wrong Theory" Claim}

The third type of theoretical criticism rests on the claim that special education applied/practical knowledge is based on the wrong theory, or that it relies too narrowly on one or more theories to the exclusion of others. Most instances of this type of criticism have been mounted by sociologists and political scientists who argue that special education depends too heavily or exclusively on theory derived from the discipline of psychology and the associated disciplines behind the field of medicine-ultimately, biology. The argument is that, by their very nature, these disciplines place the root cause of all disability and deviance within the person, and exclude from consideration causal factors that lie in the larger social and political processes external to the individual. In addition, social scientists see diagnosis, intervention, and technology based in the behavioral and biological sciences as superficial because these do nothing to assess, alter, or circumvent the social-political-cultural context of "disability."

Whereas the behavioral and biological sciences study organisms and consider disability to be an objective condition that people have, the social sciences study social and political systems and processes and consider deviance to be a subjective condition that is societally created and maintained (see 
Gould, 1982; Szasz, 1961; Goffman, 1961, 1963; Scheff, 1966; Scott, 1969; Braginsky \& Braginsky, 1971; Lemert, 1967; Davis, 1963; Wiseman, 1970; Bogdan, 1974; Gubrium, 1975; Biklen, 1977; Taylor \& Bogdan, 1977). And this is more than an academic argument. Many of the social scientists who raise the issue are ultimately concerned with the impact of social and political processes on people and society. From their perspective, in the extreme, special education in industrialized societies is an arm of education that creates and works against the social-political interests of powerless groups (Sarason \& Doris, 1979; Smith, 1985; Barton \& Tomlinson, 1984; Tomlinson, 1982; Farber, 1968).

\section{THE IMPACT OF CRITICISM OF SPECIAL EDUCATION KNOWLEDGE}

Practical criticism - mounted by parents, consumers and advocates, and, in a more limited way, special educators themselves-was successful in bringing about changes in the way special education is practiced in public education, as those changes have been embodied in PL 94-142. But, as noted, criticism of special education's practical knowledge does not resort to a critique of special education's theoretical or applied knowledge. Thus, it has had no effect on special education's unconscious assumptions. That is, although PL 94-142 brought about substantial changes in the organization and practice of special education, it rests on the same set of basic beliefs about the nature of disability, special education as a helping profession, and progress in the field. The first three assumptions - that disabilities are conditions people have, that disabled/typical is a useful and objective distinction, that special education is a rationally conceived and coordinated system that helps students who are labeled disabled—stand unaltered. Moreover, according to the fourth assumption, PL $94-142$ is perceived as improved diagnosis, intervention, and technology-an example of progress.

Unlike practical criticism, which at least has resulted in visible changes in the organization and practice of special education within public education, theoretical criticism has had few, if any, meaningful consequences for research or practice in special education. People from a number of disciplines and fields, including special education, have criticized special education's unconscious assumptions, or have attempted to convince the professional community of special education to expand its disciplinary base to include social and political theories of deviance. But no general movement has been launched to alter special education policy and practice or to reorient its research based on these insights.

Discussing the impact of theoretical criticism of special education applied research on the effectiveness of special education practice, Bogdan and Kugelmass (1984, p. 173) summarized the state of affairs succinctly by saying that, "In short, most research has been for special education (serving the field as it conceived of itself), not of special education, that is looking at the field from an alternative vantagepoint." Special education applied research leaves unanswered, and treats as unproblematic, fundamental questions about its unconscious assumptions.

Thus, on one hand is practical criticism, which has resulted in visible changes in the way special education is practiced but has had no effect on theory or the taken-forgranted assumptions that derive from it. On the other hand is theoretical criticism, which has had virtually no impact on theory, research, or practice in special education. Special education practice has been altered by PL 94-142, but only within the frame of reference of special education's traditional assumptions about the nature of disability, special education as a helping profession, and progress in the field. Does PL 94-142 represent progress? Undoubtedly it does. But progress in this sense is only a limited sort of progress; it is progress within a particular frame of reference or set of basic assumptions.

I am arguing that real progress in special education will require a different frame of reference. At a minimum, it will require that special education take seriously the critics of its theoretical and applied knowledge, and thus of its taken-for-granted assumptions. It will require criticism in the classical sense - self-reflective examination of the limits and validity of special education knowledge. But the problem is that the professional community of special education will not readily accept theoretical criticism, precisely because it contradicts its basic assumptions about the nature of disability, special education as a helping profession, and progress in the field.

Of course, one could argue that, as a professional community, special education demonstrated its ability to accept criticism - and even to engage in self-criticism - during the period leading to passage of PL 94-142. But most of that was practical criticism or criticism that could be deflected onto the regular education system. Special education could accept it because at bottom it did not contradict or conflict in any way with its basic assumptions. Theoretical criticism, however, is more difficult to accept precisely because it 
contradicts those assumptions. Moreover, the problem is more than an inability to accept theoretical criticism. It is largely an inability to understand it.

Professionals in all fields are prepared for practicewhether practice is service delivery or applied researchthrough a process that shapes their thought and behavior to conform to the established knowledge of the profession. The process requires total submission to the authority of the profession, an acceptance on faith of the profession's knowledge. Professional induction is the efficient inculcation of the inductee with a commitment to a particular way of seeing the world and operating in it.

Special education professionals-teachers, administrators, teacher trainers, applied researchers-ordinarily have difficulty understanding theoretical criticism because it is based on a view of the world and special education that falls outside of special education's established knowledge. Persons inside the professional community and their theoretical critics on the outside literally are inhabitants of different conceptual worlds. They slice up the social world differently; they speak different languages and employ different concepts. Moreover, professional autonomy means that nothing has compelled the special education professional community to listen to its critics. All judgments as to the adequacy of special education knowledge are left to the profession itself. And, of course, special education's inability to see itself as others do is not particularly unusual. This is an inherent characteristic of all professional communities. They all create and maintain their own conventionally-based reality. Each is an insulated sub-culture of conventional knowledge. Each is a way of seeing.

\section{THE CASE FOR MULTIDISCIPLINARY SPECIAL EDUCATION KNOWLEDGE}

The fact that special education can view itself from alternative vantage-points can be demonstrated through two approaches: longitudinal and cross-sectional. The longitudinal approach-looking at the same entity over time-is simple. To understand that special education can be viewed in different ways, one need only compare special education today with what it was at any given point in its past history. In this sense, the history of special education is the history of the redefinition of special education practice. We can see, for example, that special education practice in the 1940s was substantially different than it was in the 1960s, or than it is today. Here again, however, we must not lose sight of the fact that these changes have been largely changes in practice. Theoretical and applied knowledge-and thus the unconscious assumptions of the profession-have not changed.

In contrast, the cross-sectional approach looks at one entity from different perspectives. Conventional special education knowledge about the nature of disability is the result of the particular disciplinary base of theoretical knowledge that has been used and the manner in which it has been applied. Given the dominant model of professional knowledge and the nature of professional education, the special education professional community not surprisingly is deeply committed to a biological-psychological explanation of disability. Nevertheless, we know that alternative theoretical conceptualizations of deviance, and thus alternative forms of potential special education knowledge, exist. A substantial body of literature, deriving primarily from sociological, political, and cultural theories of deviance, and which provides many different perspectives on virtually every aspect of the notions of special education and "disability," is available.

Once one accepts the position that special education and "disability" can be viewed in alternative ways and, more important, that each perspective has different implications for children labeled disabled and their parents and families, the argument that special education should consider itself and its professional knowledge from alternative vantagepoints is self-evident on ethical and moral grounds. For special education to continue to rely on an exclusively biological/psychological explanation of "disability" has no defensible argument.

Today's special education knowledge is not inherently "correct." It is a matter of history-a history that could have taken a different course. If special education knowlege were to have had a broad base in, say, sociology, political science, anthropology, psychology, and biology, instead of a narrow base in psychology and biology, members of the professional community would think and act in very different ways. They would inhabit a different conceptual world, speak a different language, and employ different concepts. If this were so, the very notion of "disability" and the approach taken would be substantially different. Diagnosis, intervention, and technology would not be directed exclusively at the individual but would just as likely be directed at the conceptual and material structures, systems, and processes external to the individual. Things such as organizations, institutions, and belief systems-not just children and youth—would be targets.

Special education should expand its disciplinary base beyond psychology and biology to include the various social, 
political, and cultural sciences. Like most of the theoretical critics cited above, I believe that special education knowledge should be multidisciplinary. "Multidisciplinary" is not the same as "interdisciplinary." Interdisciplinary refers to collaboration among professionals in the performance of services to clients. The case for interdisciplinary professional practice is a familiar argument by now (see Schein, 1972) and is based on the fact that many of the challenges society faces today are so complex that no single profession can deal with them effectively. This is not to miminize the need for interdisciplinary professional practice. Given the complexity of problems in special education practice, interdisciplinary collaboration-among regular and special education practitioners, among various types of special educators, and among special education and related services professionals-is a necessity. The point to make is that special education knowledge should be multidisciplinary, as well. Special education requires a substantial reorientation of theoretical, applied, and practical knowledge, and a concomitant revision in the professional education curriculum of special education.

This reorientation would begin with a multidisciplinary theoretical critique of special education knowledge-a selfreflective examination of the limits and validity of special education knowledge from the alternative perspectives of the various social sciences. And, of course, the multidisciplinary theoretical analysis would be facilitated greatly by the fact that a number of alternative disciplinary analyses currently exist. Moreover, to be adequate, this substantially top-down analysis must incorporate the essentially bottomup practical criticism of current special education practice, opening up the possibility of uniting in one democratized discourse the interests of theorists, applied scientists, practitioners, and consumers and advocates.

Even if the professional community of special education could be persuaded to carry out a multidisciplinary theoretical critique and to adopt a multidisciplinary orientation, however, these measures would not be sufficient to reorient special education knowledge. Today, theoretical criticism and a multidisciplinary orientation are simply not enough.

\section{METATHEORETICAL CRITICISM OF SPECIAL EDUCATION KNOWLEDGE}

A multidisciplinary theoretical criticism and a multidisciplinary reorientation of special education knowledge are not sufficient because the very notions of "theory" and "discipline" themselves are under attack today. The basis of the reorientation of special education knowledge must go beyond theoretical criticism: The professional community of special education must attempt a metatheoretical critique of its professional knowledge. To understand the meaning of metatheoretical criticism, several additional concepts are introduced here. Central among these are the concepts of paradigm and paradigm shift.

\section{Paradigms and Paradigm Shifts}

For the past two decades the terms paradigm and paradigm shift have been associated most often with the influential work of Thomas Kuhn (1962, 1970a). Kuhn used these concepts in an analysis of scientific development in the physical or "hard" sciences, such as physics and chemistry. Kuhn reserved his analysis exclusively for the physical sciences, making no claim for its application to the social sciences. Nevertheless, Kuuhn's work has had a profound effect on the social sciences, despite his reluctance to apply it there.

Although the concept of a paradigm was the central element in Kuhn's analysis of scientific progress, he was neither clear nor consistent about what he meant by it. Masterman (1970) counted 21 different uses of the term in Kuhn's original work, which she reduced to three broad types of paradigms. Of the three types of paradigms - metaphysical, sociological, and construct - the metaphysical paradigm represents the broadest use of the term and subsumes the other two. A metaphysical paradigm is a total world view or gestalt within a given scientific community or sub-community.

The metaphysical paradigm is the broadest unit of consensus within a given science. It serves to define the broad parameters of the field, or subareas within a field, giving the scientist a broad orientation from which to operate. (Ritzer, 1980, p. 5)

In this sense, Kuhn used paradigm to mean a way of "seeing," a general organizing principle governing perception, a "map" that describes for scientists which entities exist (and which do not) and how they behave.

Broadly construed, then, a paradigm is a set of explicit or implicit presuppositions or basic beliefs that scientists use to provide coherence to their picture of the world and how it works. These presuppositions or basic assumptions are metatheoretical assumptions. They are metatheoretical assumptions because they are beyond, or are more fundamental than, theories themselves. Metatheoretical assumptions are more fundamental than theories because observation-which, according to the conventional view of theory, 
is the rock bottom upon which theory is founded (see Feigl, 1970) - is itself strongly influenced by a prior conceptual system of metatheoretical assumptions (see Mulkay, 1979; Shimony, 1977).

A metaphysical or metatheoretical paradigm (hereafter simply paradigm) can be thought of as a special lens through which the world can be viewed. This lens has the peculiar property that, while it may enhance the clarity with which some things can be viewed, it does not allow one to view other things. A paradigm is a particular lens, a particular way of seeing. A paradigm shift occurs when we abandon one lens (or way of seeing) for a different one. The new lens or paradigm provides a different way of seeing the world and making sense of it.

Kuhn revolutionized our understanding of scientific knowledge by using the concepts of paradigm and paradigm shift to distinguish between continuous and discontinuous scientific progress. Continuous scientific progress-what Kuhn called "normal science"-progresses by gradual additions to a knowledge base. Normal science is a highly cumulative enterprise that refines, extends, and articulates a paradigm that already exists. An accepted paradigm is essential for scientific work because it unrandomizes nature and thus permits scientists to know what data are, what methods and instruments are necessary to retrieve them, and what concepts are relevant to their interpretation (Kuhn, 1970a).

Although normal science or continuous scientific progress is the typical image of scientific work, Kuhn's thesis is that it is only a necessary prelude to discontinuous scientific progress-real scientific discovery that uncovers new and unsuspected phenomena and invents radical new theories. Discontinuous scientific progress-what Kuhn called "revolutionary science"-is characterized by discontinuous breakthroughs that demand an entirely new set of metatheoretical assumptions-or, a new paradigm-for understanding data. Discoveries of this sort begin with the recognition and extended exploration of an anomaly, which is a violation of the paradigm-induced expectations of normal science. When the anomaly comes to be seen as more than just another normal science problem, the transition to paradigm crisis has begun. As the anomaly continues to resist, many of the field's most eminent scientists come to view its resolution as the subject matter of their field, which intensifies the crisis to the point where the rules of normal science are blurred. The paradigm exists, but few practitioners now can agree entirely about what it is.

Loosening of the paradigm's rules gives rise to extraordi- nary research and philosophical analysis. Extraordinary research includes attempts to isolate and magnify the anomaly, random experimentation, and generation of speculative theories. Philosophical analysis is directed toward exposing - often for the first time- the metatheoretical assumptions that underwrite the current paradigm and the contemporary research tradition. Together, extraordinary research and philosophical analysis loosen the paradigm's stereotypes and begin to provide the incremental data necessary for a fundamental paradigm shift. Sometimes the structure these procedures give the anomaly foreshadows the shape of the new paradigm. More often, however, the new paradigm emerges all at once- "sometimes in the middle of the night, in the mind of a man deeply immersed in crisis" (Kuhn, 1970a, p. 90). In any event, the shift to a new paradigm is revolutionary science. Normal science rests on the mutual acceptance of a given paradigm among a community of scientists; revolutionary science requires a paradigm shift. After the shift, the stage is set for the process to repeat itself.

Kuhn's view of scientific development as discontinuous progress placed him at odds with the prevailing view of scientific progress and the growth of knowledge. In effect, it introduced a major anomaly into the dominant paradigm of positivist knowledge. In place of the conventional assumption of cumulative, convergent, and objective knowledge, Kuhn substituted the idea that science and knowledge are discontinuous, divergent, and subjective.

\section{The Subjectivity of Science and Knowledge}

A key element in Kuhn's original work was that the process by which one paradigm replaces another paradigm is essentially a political phenomenon, a process of persuasion and conversion, with the victorious paradigm being the one that wins the most converts (Ritzer, 1980). Thus, irrational and subjective factors may affect and even determine the emergence of a new paradigm. In the face of criticisms that he overemphasized irrationality in scientific work (see Lakatos \& Musgrave, 1970), Kuhn subsequently retreated from this position (Kuhn, 1970b). Nevertheless, it was this aspect of his analysis that was most attractive to those who have extended his work.

Using Kuhn's thesis to frame their work, proponents have argued that indeed paradigms in the physical sciences rise and fall as a result of subjective, not objective, factors (e.g., Bloor, 1976; Law, 1975; Phillips, 1973; Knorr, Krohn, \& Whitley, 1981). Krohn (1981, p. xi) summarized the first body of empirical work on scientific practice-the ethnog- 
raphic and detailed historical study of actual scientific activity-by saying that "[physical] scientists are literally constructing their world rather than merely describing it." Kuhn's work was important for what it had to say about the role of culture and tradition in the production of knowledge. His analysis of the conventional nature of knowledge and the nature of convention itself contradicted the common perception that science and knowledge are objective, and advanced the idea that both depend on their cultural context for meaning and interpretation.

Barry Barnes (1982, p. 10) noted the significance of the subculture in science, and the communal activity of the organized practitioners who sustain it, when he said that "the culture is far more than the setting for scientific research; it is the research itself." The image of the scientist as an objective and impersonal observer in the process of knowledge discovery is being replaced by the image of the scientist as craftsperson who, bound by the culture of a particular place and time, creates knowledge that is assumed to be of temporary utility and validity (Ravetz, 1971). This revised image of science and scientific work has necessarily caused a revision in the very legacy of knowledge. Once conceived as "a separate verbal and symbolic high culture [with] the power to reveal, order and enlighten . . . [it] is being brought down to earth, demystified as a human construction, in the natural as well as the social [sciences]" (Krohn, 1981, p. xii).

At this point we can begin to see the parallels between the work of the basic scientists and the work of the applied scientists and professional practitioners. The latter groups operate on the basis of received knowledge - that is, knowledge that each accepts on faith from higher levels in the hierarchy of professional knowledge. Although this is the case for applied researchers and professional practitioners, the assumption had been that the theoretical knowledge of the basic sciences was itself objective knowledge about reality. The key point to grasp is that, like the applied scientist and professional practitioner, basic scientists operate on the basis of received knowledge. Theirs is not objective knowledge but, rather, knowledge received by looking at the world through the lens of a particular paradigm or set of metatheoretical assumptions.

From Kuhn's description of the induction of physical scientists into scientific communities, we can see now that all three groups - basic scientists, applied researchers, and professional practitioners - are inducted into subcultures of conventional knowledge, which they "receive" on faith as the only way of unrandomizing the complexity of their particular worlds of practice. Like the craftsperson, each is bound by the culture of a particular place and time. Like the image of science and the legacy of knowledge, the role of basic scientist has been demystified and brought down to earth.

\section{Social Scientific Thought}

Although Kuhn reserved his conception of paradigms and paradigm shifts exclusively for the physical sciences, further extensions of his work have allowed an understanding of the paradigmatic status of the social sciences. Masterman (1970) made an important contribution in this regard in using the concept of a paradigm to distinguish four types of sciences: paradigmatic, nonparadigmatic, dual paradigmatic, and multiple paradigmatic. For Masterman, a paradigmatic science is one having broad consensus within the scientific community on a particular paradigm. Examples of a science achieving the paradigmatic state are relatively few, but some do exist. Physics is the primary example. Until the birth of the Einsteinian paradigm in this century, physics was dominated by the Newtonian paradigm. Although some scientists doubted the Newtonian paradigm, physics during the period between Newton and Einstein is perhaps as close as a science can come to the paradigmatic state.

Nonparadigmatic science is the situation in which no consensus exists on a paradigm. Before Newton, physics presumably lacked consensus and therefore was, at that point in its development, a nonparadigmatic science. The dual paradigmatic state exists immediately before a Kuhnian scientific revolution, when two paradigms - the older, crisisridden paradigm and the new, emerging paradigm - are vying for the dominance that only one of them ultimately will achieve. The Newtonian paradigm dominated physics until increasing anomalies set it up for defeat by the Einsteinian paradigm (see Clark, 1971), but at the point when both paradigms were competing for dominance, physics was a dual paradigm science.

The final type of science discussed by Masterman is the multiple paradigmatic science, in which several viable paradigms compete unsuccessfully for dominance within the scientific community. The multiple paradigm state is particularly important for our purposes because it permits differentiation between the physical and social sciences on the basis of their paradigmatic status. The various physical sciences (more or less) are paradigmatic sciences. The birth of a particular physical science can be thought of as the point at which it emerged from a nonparadigmatic state and achieved 
its paradigmatic status. From there, its history is a series of discontinuous progressions in which normal science-now posible because of paradigmatic consensus-produces the anomalies necessary to create a crisis big enough to yield a scientific revolution, and thus a new paradigm.

On the other hand, the social sciences are multiple paradigm sciences. Unlike the physical sciences, in which one paradigm dominates until crisis and revolution replace it in toto with another paradigm, multiple paradigms co-exist in the social sciences. This means that scientific revolutions in the Kuhnian sense are virtually impossible in the social sciences because there is no dominant paradigm to be overthrown. Although the social sciences always have had revolutionary ways to think, all of the paradigms for thinking about the social world emerged-relative to the way physical science paradigms emerge-more or less together. Each one is a viable way to understand the social world, and each has had its own followers.

Allegiances have shifted throughout history, and one or another paradigm has dominated particular regions of the globe. But no general consensus-and thus no single dominant paradigm of social scientific thought-has been reached. Not only has this precluded revolutionary science, but it also has made normal science more difficult because, as Ritzer (1980) noted, social scientists are forced to spend an inordinate amount of energy engaging in the politics of winning converts and defending their flanks against attack from rival paradigms.

Burrell and Morgan (1979) conceptualized the multiple paradigms in the social sciences by considering the relationship between two dimensions of intellectual tradition: philosophy of science, and theories of society. Philosophy of science is a branch of philosophy that studies the reasoning processes behind the concepts, presuppositions, and methodology of science. Among other things, philosophers of science are concerned with the consequences of scientific knowledge for matters such as our perception of reality and the validity and limits of our sources of knowledge (Angeles, 1981). Burrell and Morgan used four traditional strands of debate within philosophy of science to formulate the philosophy of science or "objective-subjective" dimension of their analysis: ontology (the nature of reality), epistemology (the nature of knowledge), human nature (the nature of human action), and methodology (the nature of inquiry). Table 1 presents the extreme positions on each of the four strands of debate.

According to Burrell and Morgan (also see Morgan \& Smircich, 1980), the realist assumes that the social world

exists "out there," independent of an individual's appreciation of it, and that it is virtually as hard and concrete as the physical world. The nominalist, in contrast, assumes that the social world external to individual cognition is made up of names, concepts, and labels that serve as tools for describing, making sense of, and negotiating the external world. The positivist seeks to explain and predict social events by searching for regularities and determinate causal relationships. Growth of knowledge is seen as essentially a cumulative process in which new information is added to the existing stock of knowledge and false hypotheses are eliminated. The anti-positivist, conversely, assumes the social world to be essentially relativistic - understandable, but only from the point of view of the individuals directly involved in the activities to be investigated. Anti-positivists reject the notion of "observer" as a valid vantage point for understanding human activities.

\section{TABLE 1 \\ The Objective-Subjective Dimension}

\section{Subjectivist Social Science}

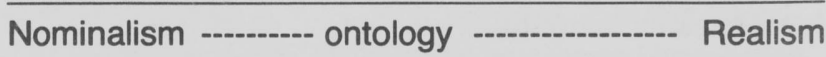
Anti-positivism ------ epistemology --------- Positivism Voluntarism ---------- human nature ----- Determinism Idiographic ---------- methodology -------- Nomothetic

Source: Burrell \& Morgan (1979, p. 3).

Determinists assume that humans respond mechanistically or even deterministically to the situations encountered in their external world. Voluntarists ascribe a much more creative human role. Free will and autonomy are assumed and humans are seen as creating their environments, controlling them rather than being controlled by them. Nomothetic methodologies are adopted by social scientists who treat the social world as if it were a hard, objective, external reality. The search is for universal laws that explain and govern the one, concrete, objective social reality that is presumed to exist. Idiographic methodologies are adopted by those who assume the importance of the subjective experience of individuals in creating their social world. The principal concern for social scientists using idiographic methodologies is to understand the ways individuals create, modify, and interpret the social world in which they find themselves.

The extreme positions of the objective-subjective dimension are reflected in two major intellectual traditions that 
have dominated social science for 200 years. Objectivist social science is logical positivism, the dominant position in the West, which:

reflects the attempt to apply the models and methods of the natural sciences to the study of human affairs. It treats the social world as if it were the natural world, adopting a "realist" approach to ontology . . . backed up by a "positivist" epistemology, relatively "deterministic" views of human nature and the use of "nomothetic" methodologies. (Burrell \& Morgan, 1979, p. 7)

The subjectivist position, German idealism, stands in complete opposition to positivism in that:

it is based upon the premise that the ultimate reality of the universe lies in "spirit" or "idea" rather than in the data of sense perception. It is essentially "nominalist" in its approach to social reality . . . "antipositivist" in epistemology, "voluntarist" with regard to human nature and it favours idiographic methods as a foundation for social analysis. (Burrell \& Morgan, 1979, p. 7)

Burrell and Morgan used the terms "sociology of regulation" and "sociology of radical change" to describe the extreme positions on their "nature of society," or "order-conflict," dimension. Table 2 differentiates between the two positions by counterposing the issues with which each is concerned.

TABLE 2

The Regulation-Radical Change Dimension

\begin{tabular}{|c|c|}
\hline $\begin{array}{l}\text { The sociology of } \\
\text { regulation is } \\
\text { concerned with: }\end{array}$ & $\begin{array}{l}\text { The sociology of } \\
\text { radical change is } \\
\text { concerned with: }\end{array}$ \\
\hline \multicolumn{2}{|c|}{ 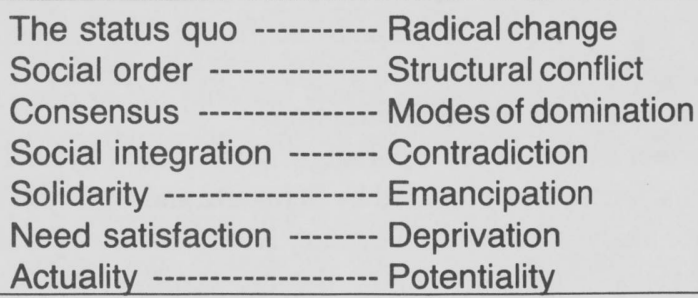 } \\
\hline
\end{tabular}

Adapted from Burrell \& Morgan (1979, p. 18).

Sociology of regulation - the dominant position in the West-reflects the value position of theorists who are concerned about explaining society's underlying unity and cohesion. Conversely, theorists of the sociology of radical change view modern society as being characterized by conflict, modes of domination, and contradiction. They are concerned with people's emancipation from existing social structures.

Ritzer (1980) proposed another way to think about the same intellectual territory coverd in the Burrell and Morgan analysis. He used the same objective-subjective dimension but substituted a "levels of social reality" dimension in place of Burrell and Morgan's order-conflict dimension. Ritzer used a "macroscopic-microscopic" dimension in which the magnitude of social phenomena-that is, social reality ranging from whole societies to social acts — differentiates among theoretical positions. Ritzer's "microscopic" level corresponds to the "order" end of Burrell and Morgan's order-conflict dimension, and his "macroscopic" level corresponds to the "conflict" position. In either case, when the two dimensions are counterposed orthogonally, they produce four paradigms of social scientific thought (see Figure 1) based on mutually exclusive views of the social world and how it might be investigated. Each of the four paradigms - what we will refer to, following Burrell and Morgan, as the functionalist, interpretive, humanist, and structuralist paradigms-rests on a fundamentally different set of metatheoretical assumptions about the nature of science and of society (i.e., the nature of social science).

The functionalist paradigm is the dominant framework for social science in the Western world. It is firmly grounded in the sociology of regulation, takes a more or less microscopic view of social reality, and studies its subject matter from an objectivist point of view. It seeks to provide rational explanations of social affairs using an approach to science premised in the tradition of logical positivism. As such, it:

... reflects the attempt, par excellence, to apply the models and methods of the natural sciences to the study of human affairs . . . The functionalist approach to social science tends to assume that the social world is composed of relatively concrete empirical artifacts and relationships which can be identified, studied and measured through approaches derived from the natural sciences. (Burrell \& Morgan, 1979, p. 26)

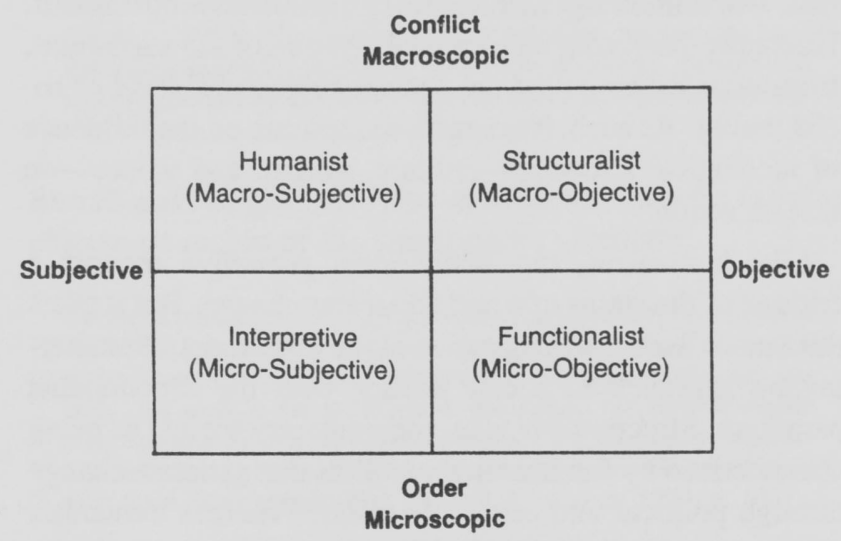

Adapted from Burrell \& Morgan (1979, p. 29) and Ritzer (1980, p. 239). FIGURE 1

Four Paradigms of Social Scientific Thought 
The functionalist paradigm is equivalent to what Ritzer referred to as the "micro-objective" approach to social science. Theorists operating from this vantage-point are concerned with explaining social life by concentrating on microscopic social phenomena such as patterns of behavior, action, and interaction.

Interpretive theorists are only implicitly committed to regulation and order. They assume that the social world is cohesive, ordered, and integrated, but (unlike the functionalists) they are oriented toward understanding the ongoing processes through which humans subjectively create their social world. The interpretive paradigm addresses the same social issues as the functionalist paradigm, but it is concerned with understanding the essence of the everyday world as an emergent social process. When a social world outside the consciousness of the individual is recognized, it is regarded as a network of assumptions and intersubjectively shared meanings. The interpretive paradigm corresponds to Ritzer's micro-subjective level of social reality. Theorists of this persuasion are concerned with understanding the various facets of the social contruction of reality - the way people create and share meaning (see Berger \& Luckmann, 1967).

Although humanists share a view of social science with the interpretive paradigm, their frame of reference is the sociology of radical change. The humanist paradigm views society with a prime concern toward the importance of transcending the limitations of existing social structures. Humanism views the ideological superstructures with which people interact as a screen between them and their true consciousness. Thus, society is viewed as being antihuman-as inhibiting human development and fulfillment. Humanist theorizing centers on a critique of the status quo, from what Ritzer called the "macro-subjective" level of social reality. As such, humanists concentrate on the influence of ideological structures-culture, norms, and values-on human action.

Like humanism, the structuralist paradigm mounts a critique of the status quo and advocates change. But it takes this stance from the perspective of the objectivist, thus sharing an approach to social science with the functionalist paradigm. Structuralists view contemporary society as being characterized by fundamental conflicts that generate change through political and economic crisis. Whereas humanists are concerned with ideological structures and individual consciousness, structuralists focus their critique upon material structures-including social arrangements-and are concerned with the consciousness of entire classes of individu- als. Structuralist theorists occupy Ritzer's macro-objective level and approach social science with a concern to explain social entities such as society, law, bureaucracy, architecture, technology, and language.

The basic point is that the approach social scientists take depends on their metatheoretical assumptions with respect to the nature of the social world and how it may be investigated. The particular combination of metatheoretical assumptions explicitly or, as is most often the case, implicitly defines the paradigm and provides the frame of reference of social scientists who work within it. Each paradigm produces knowledge that is based on a unique brand of insight. Each paradigm is a way of seeing.

\section{The Paradigm Shift in Science and Civilization}

Using the scheme presented in Figure 1 as a backdrop, we can begin to see the radical implications of the ideas of paradigms and paradigm shifts. From Kuhn, and the extensions of his original work, we can see that the very notions of paradigm and paradigm shift support a subjectivist philosophy of science. Whether we think of the process of total paradigm replacement in the physical sciences, or the process of competitive co-existence among multiple paradigms in the social sciences, the idea that paradigms exist in the minds of humans, who then operate under their received meaning, is the type of thinking about knowing that is possible only from a subjectivist view of science and knowledge. The concepts of paradigm and paradigm shift can exist only in the interpretive and humanist paradigms. They are conceptually impossible in the two objectivist paradigms, which assume a single objective reality as one of their metatheoretical assumptions.

Further evidence for a paradigm shift in the physical and social sciences was provided by Schwartz and Ogilvy (1979) in their analysis of the 20th century Kuhnian paradigm shifts in physics, chemistry, brain theory, ecology, evolution, mathematics, philosophy, politics, psychology, linguistics, religion, consciousness, and the arts. They argued that, taken together, the manifestations of these disciplinary shifts characterize an emergent world view in the formal disciplines that is moving away from objectivism and positivism and toward a subjectivist view of science and knowledge.

At yet a broader level of human consciousness, Schwartz and Ogilvy argued that the values inherent in the disciplinary paradigm shift foreshadow an emergent shift in the entire consciousness of Western civilization. Evidence supporting this assertion, of course, is all around us. Our current world 
view itself is the result of the 17 th century scientific revolutions that collectively became the Enlightenment. The Newtonian world view emanating from that paradigm shift is reflected today in every aspect of our social order. Its models and metaphors are embedded in our language, our history, our science. These mental maps of the world are the foundations of Western values and beliefs - the very values and beliefs that made the functionalist paradigm the dominant social science paradigm in the West. In the future, according to Schwartz and Ogilvy, Western values and beliefs will conform to the subjectivist metatheoretical assumptions.

\section{The Meta-Leap to Antifoundational Knowledge}

According to Schwartz and Ogilvy, even though science and civilization have shifted paradigms before, the current paradigm shift is even more revolutionary because this time the patterns of change have themselves changed. Not only do we appear to be at the threshold of a new paradigm or world view, but we know that there are paradigms. This awareness itself is part of the new paradigm because it took a shift to the subjectivist paradigms before we could comprehend a paradigm or a paradigm shift. Our current paradigm amounts to the view that there are no such things as paradigms; only the "facts" are important-seeing is believing.

But now Western science has begun to take seriously the proposition that what we believe determines much of what we see, and that the notion of an objective science is illusionary. Until this century, the assumption was that we could study the social world objectively by using the methods and models of the physical sciences. Now we have discovered that even in the physical world inquiry affects results. Our disciplines themselves are not neutral to the world. Believing is seeing.

The common view that social science is a neutral, technical process that reveals or discovers knowledge is being replaced by an appreciation of social sciences as a distinctively human process through which knowledge is created. Each paradigm produces a unique brand of insight. Historically, debate in the social sciences has been premised on a foundational view of knowledge, which has led to arguments over the "best" way of doing research or the "best" theory to explain social phenomena. But today, debate is moving beyond considerations of a single research method, theory, or paradigm, and social scientists are beginning to call for an antifoundational, reflective discourse about and appreciation of the variety of available research logics, theoretical positions, and paradigmatic perspectives (see Morgan, 1983; Soltis, 1984). Moreover, recognition of the selection of a particular research strategy, theory, or paradigm as problematic and value-laden is forcing us to recognize social science as a political, moral, and ethical undertaking as much as a technical one.

\section{The Paradigmatic Status of Special Education Knowledge}

Special education's disciplinary base in biology (medicine) and psychology yields an approach to diagnosis, intervention, and technology grounded in diagnostic-prescriptive teaching and behavioristic theory. Diagnosticprescriptive teaching is the attempt to design instructional programs on the basis of test performances. Of the two theoretical models within the diagnostic-prescriptive approach-ability-training and task-analysis-Salvia and Ysseldyke (1981) noted the preference in special education for the latter because of the lack of reliable and valid norm-referenced assessment devices necessary to actualize the ability training model.

The task-analysis model is based on the application of behavioristic theory to instruction in specific skills. Complex instructional goals are task-analyzed into subskills and taught using a hierarchy of behavioral procedures for skill acquisition (see White \& Haring, 1976). The teacher is conceptualized as a technician applying a technology of teaching commonly referred to as "systematic instruction," which:

\footnotetext{
. has grown out of the experimental analysis of behavior, which, as a scientific discipline, sought to find a systematic interpretation of human behavior based on generalized principles, or laws, of behavior. The goal of this search for laws of behavior was much the same as in any other branch of science - to make reliable predictions (Skinner, 1953). The development of behavior analysis has been rigorously scientific, beginning with basic laboratory research and slowly generalizing the results to social situation. (Haring, 1978, p. 21)
}

Burrell and Morgan (1979) locate behaviorism in the extreme objectivist region of the functionalist paradigm.

\footnotetext{
Skinner's perspective is a highly coherent and consistent one in terms of the four strands of the subjective-objective dimension of our analytical scheme. Ontologically, his view is firmly realist; epistemologically, his work is the archetype of positivism; his view of human nature reflects a determinism of an extreme form; the highly nomothetic methodology reflected in his experimental approach is congruent with these other assumptions. (Burrell \& Morgan, 1979, p. 103)
}

This places special education knowledge in the most extreme objectivist region of the functionalist paradigm, as shown in Figure 2 (see also Heshusius, 1982). 


\begin{tabular}{|c|c|}
\hline $\begin{array}{c}\text { Humanist } \\
\text { (Macro-Subjective) }\end{array}$ & $\begin{array}{c}\text { Structuralist } \\
\text { (Macro-Objective) }\end{array}$ \\
\hline Interpretive \\
(Micro-Subjective) & $\begin{array}{c}\text { Functionalist } \\
\text { (Micro-Objective) } \\
\text { Special } \\
\text { Education } \\
\text { Knowledge }\end{array}$ \\
\hline
\end{tabular}

FIGURE 2

Paradigmatic Status of Special Education Knowledge

\section{THE CASE FOR MULTIPARADIGMATIC, MULTIDISCIPLINARY SPECIAL EDUCATION KNOWLEDGE}

Special education can and should view itself from alternative vantage-points. You will recall that the fact that special education can view itself from alternative vantage-points was demonstrated using both a longitudinal and a cross-sectional explanation. The basic concept to grasp about the cross-sectional explanation at this point is that, in addition to the possibility of considering special education knowledge from a number of alternative disciplines, the very nature of those disciplines necessitates consideration of special education knowledge from the multiple paradigms of social scientific thought. As we have seen, to consider any of the social science disciplines as a unitary body of thought is simply inadequate.

Once one accepts the position that special education can be viewed in alternative disciplinary ways, and that each perspective has different implications for the lives of children labeled disabled and their parents and families, there is no morally or ethically defensible argument for special education to continue to rely on an exclusively biological/ psychological interpretation of "disability." At this point we can extend the moral and ethical argument by referring to the multiple paradigmatic status of the social sciences and the notion of antifoundational knowledge. That is, given that we know that multiple paradigms exist in the social sciences, and that no particular paradigm is inherently correct, and that each paradigm has different implications for children labeled disabled and their parents and families, there is no morally defensible argument for the special edu- cation community to rely exclusively on a functionalist conceptualization of the social sciences.

Special education should expand its disciplinary base beyond psychology and biology to include the various social, political, and cultural sciences. At a minimum, special education knowledge should be multidisciplinary. But given the multiparadigmatic status of the social sciences and the antifoundational implications of the paradigm shift, an adequate response would require that special education adopt a multiparadigmatic, multidisciplinary stance. This stance would begin with a multiparadigmatic, metatheoretical critique of special education knowledge - an antifoundational, self-reflective examination of the limits and validity of special education knowledge from the alternative perspectives of the multiple paradigms of social scientific thought. And it would end with a democratized, multiparadigmatic, multidisciplinary reorientation of all levels of special education knowledge and concomitant modifications in the curriculum of special education professional education. This reorientation of special education professional knowledge would produce a community of special education professionals who think and act in ways that are substantially different from their contemporary counterparts.

But, of course, a number of factors are working against the possibility of a reorientation of special education knowledge. Paradigm shifts take time and are bitterly resisted. Moreover, the meta-leap to antifoundational knowledge itself requires a prior paradigm shift. Nevertheless, as we have seen, there are some encouraging developments on all of these fronts. In fact, there even has been some movement in the field of special education, both at the level of practice (Heshusius, 1982) and at the level of applied research (Stainback \& Stainback, 1984). In both cases, the argument has been for a shift from the functionalist to the interpretive paradigm (refer to Figure 2), which of course reflects the broader paradigm shift in science and civilization.

As might be expected from the foregoing discussion, the (published) reactions of the special education community to these proposals has been decidedly negative (see Ulman \& Rosenberg, 1986; Simpson \& Eaves, 1985). In both cases, the defenders of the prevailing functionalist paradigm evaluate and dismiss the proposals of the advocates for the interpretive paradigm exclusively on the basis of functionalist criteria, which they implicitly assume to be foundational-and thus the only criteria that exist. They demonstrate no recognition of the possibility of alternative frames of reference, to say nothing of the possibility of antifoundational knowledge. Although the original proposals and the advocates' responses to the defenders' reactions 
to them (Heshusius, 1986; Stainback \& Stainback, 1985) were informative and thought provoking, the exchange could hardly be called a discourse. Exchanges like this serve the purpose of educating the field and introducing anomalies, but what is needed is a sustained discourse in which all participants recognize the existence-and the moral and political implications - of multiple paradigms and antifoundational knowledge.

If an informed discourse of this nature could be initiated and sustained in a manner that would enhance special education's capacity for reflective self-criticism, two additional problems potentially would arise. First, there is the danger of the discourse becoming a substitute for action. Given the moral and political implications of the nature of special education knowledge, we do not have the luxury of time; every day counts. Second, there is the danger that the discourse will remain at the level of paradigms. As Morgan and Smircich (1980) noted, such a debate might lead to merely replacing one dominant paradigm with another dominant paradigm. We must not lose sight of the implications of antifoundational knowledge. The discourse must be raised to the meta-level of the multiple paradigms of social scientific thought and not be permitted to degenerate into a narrow debate over "the best paradigm."

Finally, even if such a discourse could be mounted and sustained to the point at which it would produce a fundamental and ongoing reorientation of special education knowledge and professional education, it would not be sufficient to substantially alter the actual practice of special education. Special education is not an island. It is merely a subsystem within the larger system of public education. Criticism of special education knowledge and practice necessarily will spill over into criticism of the knowledge base and practice of general education. In a sense, this article is a start in that direction, for virtually everything that has been said in it applies equally well to general education knowledge.

In summary, I believe that special education knowledge should be paradigmatic and multidisciplinary. Arriving at this point will require the initiation of a multiparadigmatic, metatheoretical critique of special education knowledge in the context of a democratized, informed, sustained discourse on the moral, ethical, and political implications of the choice of a frame of reference on the lives of children and youth and their parents and families. And it will be essential to expand the critique and the discourse to the entire system of public education in this country.

\section{REFERENCES}

Algozzine, B. (1976). The disturbing child: What you see is what you get? Alberta Journal of Education Research, 22, 330-333.

Algozzine, B. (1977). The emotionally disturbed child: Disturbed or disturbing? Journal of Abnormal Child Psychology, 5 (2), 205-211.

Apter, S.J. (1982). Troubled children, troubled systems. New York: Pergamon Press

Ballard-Campbell, M., \& Semmel, M. (1981, August). Policy research and special education: Research issues affecting policy formation and implementation. Exceptional Education Quarterly, pp. 59-68.

Barnes, B. (1982). T.S. Kuhn and social science. New York: Columbia University Press

Barton, L., \& Tomlinson, S. (Eds.). (1984). Special education and social interests. London: Croom-Helm.

Berger, P.L., \& Luckmann, L. (1967). The social construction of reality. New York: Doubleday.

Biklen, D. (1977). Exclusion. In B. Blatt, D. Biklen, \& R. Bogdan (Eds.), An alternative textbook in special education. Denver: Love Publishing.

Biklen, D. (Ed.). (1985). Achieving the complete school: Strategies for effective mainstreaming. New York: Columbia University.

Blatt, B., \& Kaplan, F. (1966). Christmas in purgatory. Boston: Allyn \& Bacon.

Bloor, D.C. (1976). Knowledge and social imagery. London: Routledge \& Kegan Paul.

Bogdan, R. (1974). Being different: The autobiography of Jane Fry. New York: John Wiley.

Bogdan, R., \& Kugelmass, J. (1984). Case studies of mainstreaming: A symbolic interactionist approach to special schooling. In L. Barton \& S. Tomlinson (Eds.), Special education and social interests (pp. 173 191). London: Croom-Helm

Braginsky, D., \& Braginsky, B. (1971). Hansels and Gretels. New York: Holt, Rinehart \& Winston.

Burrell, G., \& Morgan, G. (1979). Sociological paradigms and organizational analysis. London: Heinemann Educational Books Ltd.

Clark, D.L. (1985). Emerging paradigms in organizational theory and research. In Y.S. Lincoln (Ed.), Organizational theory and inquiry: The paradigm revolution (pp. 43-78). Beverly Hills, CA: Sage Publications.

Clark, R. (1971). Einstein: The life and times. New York: Avon Books

Davis, F. (1963). Passage through crisis. Indianapolis: Bobbs-Merrill.

Dunn, L.M. (1968). Special education for the mildly retarded: Is much of it justifiable? Exceptional Children, 35, 5-22.

Farber, B. (1968). Mental retardation: Its social context and social consequences. Boston: Houghton Mifflin.

Feigl, H. (1970). The "orthodox" view of theories: Remarks in defense as well as critique. In Radnew \& Winokur (Eds.), Minnesota studies in the philosophy of science (Vol. 4). Minneapolis: University of Minnesota Press.

Glazer, N. (1974). The schools of the minor professions. Minerva, 12, (3), 346-364

Goffman, E. (1961). Asylums: Essays on the social situation of mental patients and other inmates. Garden City, New York: Doubleday/Anchor Books.

Goffman, E. (1963). Stigma. Englewood Cliffs, NJ: Prentice-Hall.

Gould, S.J. (1982). The mismeasure of man. New York: W.W. Norton.

Gubrium, J. (1975). Living and dying at Murray Manor. New York: St. Martin's Press.

Haring, N.G. (1978). Behavior of exceptional children: An introduction to special education. Columbus, OH: Charles E. Merrill. 
Heshusius, L. (1982). At the heart of the advocacy dilemma: A mechanistic world view. In Exceptional Children, 49(1), 6-13.

Heshusius, L. (1986). Paradigm shifts and special education: A response to Ulman and Rosenberg. Exceptional Children, 52(5), 461-465.

Hobbs, N. (1975). The futures of children: Categories, labels, and their consequences. San Francisco: Jossey-Bass.

Knorr, K.D., Krohn, R., \& Whitley, R. (Eds.). (1981). The social process of scientific investigation. Boston: D. Reidel Publishing Co.

Krohn, R. (1981). Introduction: Toward the empirical study of scientific practice. In K.D. Knorr, R. Krohn, \& R. Whitley (Eds.), The social process of scientific investigation ( $\mathrm{pp}$. vii- $\mathrm{xxv}$ ). Boston: D. Reidel Publishing.

Kuhn, T.S. (Ed.). (1962). The structure of scientific revolutions (1st ed.). Chicago: University of Chicago Press.

Kuhn, T.S. (Ed.). (1970a). The structure of scientific revolutions ( $2 \mathrm{nd}$ ed.). Chicago: University of Chicago Press.

Kuhn, T.S. (1970b). Reflections on my critics. In I. Lakatos \& A. Musgrave (Eds.), Criticism and the growth of knowledge. Cambridge: Cambridge University Press.

Lakatos, I., \& Musgrave, A. (Eds.). (1970). Criticism and the growth of knowledge. Cambridge: Cambridge University Press.

Law, J. (1975). Is epistemology redundant? Philosophy of the Social Sciences, 5, 317-337.

Lemert, E. (1967). Human deviance, social problems, and social control. Englewood Cliffs, NJ: Prentice-Hall.

Masterman, M. (1970). The nature of a paradigm. In I. Lakotos \& A. Musgrave (eds.), Criticism and the growth of knowledge. Cambridge: Cambridge University Press.

Mercer, J.R. (1973). Labeling the mentally retarded. Berkeley: University of California Press.

Morgan, G. (Ed.). (1983). Beyond method: Strategies for social research. Beverly Hills, CA: Sage Publications.

Morgan, G., \& Smircich, L. (1980). The case for qualitative research. Academy of Management Review, 5, 491-500.

Mulkay, M.J. (1979). Science and the sociology of knowledge. London: Allen \& Unwin.

Phillips, D. (1973). Paradigms, falsifications and sociology. Acta Sociologica, 16, 13-31.

Ravetz, J.R. (1971). Scientific knowledge and its social problems. Oxford: Clarendon Press.

Rhodes, W.C. (1970). A community participation analysis of emotional disturbance. Exceptional Children, 36, 306-314.

Rist, R., \& Harrell, J. (1982). Labeling and the learning disabled child: The social ecology of educational practice. American Journal of Orthopsychiatry, 52 (1), 146-160.

Ritzer, G. (1980). Sociology: A multiple paradigm science (rev. ed.). Boston: Allyn \& Bacon.

Ross, A.O. (1980). Psychological disorders of children (2nd ed.). New York: McGraw-Hill.

Salvia, J., \& Ysseldyke, J.E. (1981). Assessment in special and remedial education. Boston: Houghton Mifflin.

Sarason, S.B., \& Doris, J. (1979). Educational handicap, public policy, and social history. New York: Free Press.

Scheff, T.J. (1966). Being mentally ill: A sociological theory. Chicago: Aldine Publishing.
Schein, E.H. (1972). Professional education. New York: McGraw-Hill. Schon, D.A. (1984). The crisis of professional knowledge and the pursuit of an epistemology of practice (Report for the Harvard Business School). Cambridge: Harvard.

Schrag, P., \& Divorky, D. (1975). The myth of the hyperactive child. New York: Pantheon.

Schwartz, P., \& Ogilvy, J. (1979). The emergent paradigm: Changing patterns of thought and belief (Analytic Report 7, Values and Lifestyle Program). Menlo Park, CA: SRI International.

Scott, R. (1969). The making of blind men. New York: Russell Sage Foundation.

Shimony, A. (1977). Is observation theory-laden? A problem in naturalistic epistemology. In R.G. Colodny (Ed.), Logic, laws and life. Pittsburgh: University of Pittsburgh Press.

Simpson, R.G., \& Eaves, R.C. (1985). Do we need more qualitative research or more good research? A reaction to Stainback and Stainback. Exceptional Children, 51 (4), 324-329.

Skinner, B.F. (1953). Science and human behavior. New York: Free Press.

Smith, J.K. (1984). The problem of criteria for judging interpretive inquiry. Educational Evaluation \& Policy Analysis, 6 (4), 379-391.

Soltis, J.F. (1984, December). On the nature of educational research. Educational Researcher, pp. 5-10.

Stainback, S., \& Stainback, W. (1984). Broadening the research perspective in special education. Exceptional Children, 50, 400-408.

Stainback, S., \& Stainback, W. (1985). Quantitative and qualitative methodologies: Competitive or complementary? A response to Simpson and Eaves. Exceptional Children, 51(4), 330-334.

Swap, S. (1978). The ecological model of emotional disturbance in children: A status report and proposed synthesis. Behavioral Disorders, 3 (3), 156-186.

Szasz, T.S. (1961). The myth of mental illness. New York: Hoeber-Harper.

Taylor, S., \& Bogdan, R. (1977). A phenomenological approach to "mental retardation." In B. Blatt, D. Biklen, \& R. Bogdan (Eds.), An alternative textbook in special education. Denver: Love Publishing.

Tomlinson, S. (1982). A sociology of special education. Boston: Routledge \& Kegan Paul.

Turnbull, H.R. (1986). Free appropriate education: The law and children with disabilities. Denver: Love Publishing.

Ulman, J.D., \& Rosenberg, M.S. (1986). Science and superstition in special education. Exceptional Children, 52(5), 459-460.

Weick, K.L. (1985). Sources of order in underorganized systems. In Y.S. Lincoln (Ed.), Organizational theory and inquiry: The paradigm revolution (pp. 106-136). Beverly Hill, CA: Sage Publications.

White, O.R., \& Haring, N.G. (1976). Exceptional teaching: A multimedia training package. Columbus, $\mathrm{OH}$ : Charles E. Merrill.

Wiseman, J. (1970). Stations of the lost. Englewood Cliffs, NJ: PrenticeHall.

The ideas set forth in this article are incorporated within a forthcoming book (Edward L. Meyen and Thomas M. Skrtic, co-editors and authors), to be published by Love Publishing Company in 1987. 